Reseña de Fronteras, espacios de interacción en las tierras bajas del sur de América, de Lidia Nacuzzi y Carina Lucaioli (compiladoras). Buenos Aires, Publicaciones de la Sociedad Argentina de Antropología, 2010. 249 páginas (ISBN 978-987-1280-16-2)

\title{
Florencia Carlón
}

\section{(2) OpenEdition}

\section{Journals}

Electronic version

URL: http://journals.openedition.org/corpusarchivos/897

DOI: 10.4000/corpusarchivos.897

ISSN: 1853-8037

Publisher

Diego Escolar

\section{Electronic reference}

Florencia Carlón, « Reseña de Fronteras, espacios de interacción en las tierras bajas del sur de América, de Lidia Nacuzzi y Carina Lucaioli (compiladoras). Buenos Aires, Publicaciones de la Sociedad Argentina de Antropología, 2010. 249 páginas (ISBN 978-987-1280-16-2) », Corpus [En línea], Vol 1, No 1 | 2011, Publicado el 30 junio 2011, consultado el 30 abril 2019. URL : http://journals.openedition.org/ corpusarchivos/897 ; DOI : 10.4000/corpusarchivos.897

This text was automatically generated on 30 April 2019. 


\title{
Reseña de Fronteras, espacios de interacción en las tierras bajas del sur de América, de Lidia Nacuzzi y Carina Lucaioli (compiladoras). Buenos Aires, Publicaciones de la Sociedad Argentina de Antropología, 2010. 249 páginas (ISBN 978-987-1280-16-2)
}

\author{
Florencia Carlón
}

\begin{abstract}
Fronteras, espacios de interacción en las tierras bajas del sur de América es una compilación de Carina Lucaioli y Lidia Nacuzzi. A la introducción escrita por esta última, siguen una serie de artículos que forman parte de los estudios doctorales desarrollados por integrantes de un mismo equipo de investigación que se encuentran en diferentes instancias del proceso investigativo. Esto se traduce en una variedad de artículos, que en algunos casos resultan más complejos o completos que otros. Sin embargo, y a pesar de ello, mantienen una línea en común al focalizar en el aspecto territorial de los 'espacios de frontera' que integraban las tierras bajas de América del Sur. El hincapié hecho en el concepto de 'espacio' y no sólo de 'frontera' se vincula con la percepción de éstas como zonas permeables y en continuo reacomodamiento territorial y poblacional (Quijada 2002). Los artículos están acompañados de mapas que permiten seguir los procesos desarrollados en las fronteras y períodos en cuestión. Vale señalar que, quizás justamente por ahondar en el aspecto territorial -no sólo los autores de esta compilación sino todos aquellos que nos dedicamos a períodos pre-estatales- deberíamos dejar de utilizar mapas con divisiones administrativas actuales.
\end{abstract}


2 Respecto a las temáticas tratadas en la compilación, Lucaioli y Spota se ocupan, en diferentes períodos y desde diversas preocupaciones, del amplio territorio que constituyó la frontera chaqueña, mientras que Irurtia y Enrique hacen lo propio con el espacio pampeano-patagónico. Barbuto aborda la frontera sur de Córdoba y Latini la denominada frontera de la 'Cuenca del Plata' (integrada por el Río de La Plata, delta del Paraná, el litoral argentino, la Banda Oriental y el estado de Río Grande do Sul de Brasil). Este último innova en el re-corte espacial, al considerar esta amplia área de estudio como un 'espacio de frontera'.

3 Cada uno de los autores realiza un recorte temporal específico que permite visualizar momentos concretos en dichas fronteras, así como sus particularidades y transformaciones. A partir de relatos de viajeros y expedicionarios, Latini se ocupa del momento inicial de conquista de la 'Cuenca del Plata'. El autor pone de manifiesto los factores que incentivaron la exploración de este espacio, tales como la mítica leyenda de 'la ciudad de la plata', que luego daría el nombre al río y al propio virreinato. Haciendo foco en las estrategias de creación y reformulación que desplegaron tanto nativos como colonizadores, encuentra que la frontera de la 'Cuenca del Plata' fue un espacio de comunicación e intercambio, además de conflicto, donde es posible divisar procesos de etnogénesis, en el sentido en que lo entiende Guillaume Boccara (2003).

4 También Lucaioli se ocupa de una extensa región construida a partir de mitos de riqueza y metales preciosos: la frontera chaqueña. La autora subdivide en tres las áreas fronterizas del chaco (frontera nororiental, occidental y frontera sur), las que fueron el resultado de la organización administrativa de la región. Según Lucaioli, esta subdivisión llevó al ensayo de diferentes políticas de frontera con los grupos nativos que la habitaban. Desde los inicios de la conquista europea hasta el siglo XVIII, la autora indaga los diversos frentes de colonización de la región y las estrategias de cada uno de ellos, en función de las necesidades y los recursos disponibles, así como de las características del heterogéneo conglomerado étnico que habitaba dicho espacio.

5 Los artículos de Enrique e Irurtia se abocan a espacios geográficos que hoy día se consideran parte de una misma unidad de análisis por las interconexiones que existían entre ellos desde tiempos pre-hispánicos: la frontera pampeana y norpatagónica. Sus enfoques resultan complementarios, ya que mientras Enrique se centra en las exploraciones y la visión que el colonizador creó sobre un espacio geográfico que para el siglo XVIII aún le resultaba desconocido, Irurtia reconstruye cómo los nativos fueron percibiendo al 'huinca' y modificando la imagen del mismo a partir de los cambios operados en el siglo XIX, con el avance territorial sobre pampa y Patagonia.

Por último, los artículos de Spota y Barbuto, aunque en espacios diferentes (Chaco y sur de Córdoba), nos trasladan al período de consolidación del Estado nacional, focalizando en los esfuerzos realizados desde el Estado para lograr el control de las 'fronteras interiores'.

7 Sus preocupaciones también difieren. Spota se ocupa del avance militar que permitió el control definitivo sobre la región chaqueña - proceso también conocido como 'pacificación del desierto verde'- y de las estrategias desplegadas para subordinar a los grupos indígenas que lo habitaban. Por su parte, Barbuto, en un espacio de frontera acotado como es el Río Cuarto en el sur de Córdoba, pone de relieve la resistencia que ofrecieron sectores subalternos, tanto criollos como indígenas, al nuevo orden en construcción. La autora indaga acerca de las Guardias Nacionales como parte de los 
elementos de control social desplegados por el Estado, y encuentra en los malones indígenas y las montoneras criollas diversas formas de resistencia a ese pretendido orden.

En síntesis, en Fronteras, espacios de interacción en las tierras bajas del sur de América podemos interiorizarnos sobre los procesos vivenciados en los espacios que conformaron las fronteras con los grupos indígenas autónomos hasta el momento de consolidación del Estado argentino. Como menciona una de sus compiladoras, el foco de la obra está puesto, sobre todo, en la sociedad colonizadora. Y, si bien deja en claro que dicho enfoque es una elección, nos quedamos con ganas de saber más acerca de los grupos nativos con los que interactuó la sociedad colonizadora a lo largo de casi tres siglos.

\section{BIBLIOGRAPHY}

Boccara, G. (2003). Mestizaje y etnogénesis en las Américas, en: Mandrini, R. y Paz, C. (Comps.) Las fronteras hispano criollas del mundo indígena latinoamericano en los siglos XVI-XIX (pp. 63-108). Tandil: CEHIR/UNS/ IEHS .

Quijada, M. (2002). Repensando la frontera sur argentina: concepto, contenido, continuidades y discontinuidades de una realidad espacial y étnica (siglos XVIII-XIX), Revista de Indias 62, 103-142. Madrid: CSIC.

\section{AUTHOR}

\section{FLORENCIA CARLÓN}

\section{CEI/UNQ/CONICET}

Correo electrónico: florcarlon@hotmail.com 